\title{
DIREITOS ADQUIRIDOS POR COMUNIDADES INDIGENAS AO LONGO DA HISTORIA DO BRASIL
}

\author{
Rachel L. Q. Chacur, Andreas G. F. Miranda
}

Universidade do Oeste Paulista - UNOESTE, curso de Direito, Presidente Prudente, SP. E-mail: andreasferreira50@gmail.com

\section{RESUMO}

Este artigo tem por objetivo expor algumas das garantias adquiridas pelas comunidades indígenas ao longo da historia do nosso país, na tentativa de elucidar a importância da vigência desses direitos para o bem estar do índio e sua comunidade. O trabalho analisa varias áreas do direito, que se mostraram instrumentos necessários para a validação da cultura e proposição de direitos aos grupos indígenas brasileiros.

Palavras-chave: Indígenas. Garantias. Direitos adquiridos. Constituição. Comunidades

\section{RIGHTS ACQUIRED BY INDIGENOUS COMMUNITIES THROUGH THE HISTORY OF BRAZIL}

\begin{abstract}
This article aims to expose some of the securities acquired by the indigenous communities throughout the history of our country, in an attempt to elucidate the importance of these rights for the welfare of the Indian and his community. The paper analyzes several areas of law, which were necessary tools for validation of culture and proposal of rights to indigenous groups.
\end{abstract}

Keywords: Indigenous. Guarantees. Acquired rights. Constitution. Communities.

\section{INTRODUÇÃO}

Ao longo da historia do Brasil como Estado Democrático de direito, varias garantias à população do país foram criadas, dentre essas notamos no texto constitucional as que temos como básicas sendo: saúde, educação e lazer. Essas garantias estendem-se a todos os brasileiros, incluindo as comunidades indígenas, visando beneficiar e garantir direitos exclusivos a este grupo, algumas constituições trouxeram em seus textos artigos específicos para garantias básicas que são de suma necessidade para este grupo, além das acima citadas, algumas garantias próprias das comunidades indígenas são as de: terras devidamente demarcadas e proteção à cultura do índio. Para que tais direitos fossem amplamente difundidos uma serie de aparatos aos índios foram criados.

O objetivo do presente trabalho é expor algumas das garantias adquiridas pelas comunidades indígenas ao longo da historia do nosso país, na tentativa de elucidar a importância da vigência desses direitos para o bem estar do índio e sua comunidade.

\section{ATUAL SITUAÇÃO DOS INDÍGENAS}

A constituição Federal de 1988 garante e assegura uma serie de direitos ao índio e sua comunidade, vários são os artigos que expressam tais garantias, podemos notar que não são assegurados apenas direitos fundamentais a esse grupo, tratando-se de um grupo especial é fundamental que garantias especiais sejam tipificadas para melhoria da vida das comunidades indígenas brasileira.

Colloquium Socialis, Presidente Prudente, v. 01, n. Especial 2, Jul/Dez, 2017, p.273-277. DOI: 10.5747/cs.2017.v01.nesp2.s0148 
As garantias aos índios estão presentes na atual constituição a partir do titulo III onde é disposto sobre a organização do Estado, no artigo 20 que dispõe sobre os bens da União, é garantido no inciso XI, às terras tradicionalmente ocupadas por índios, dentro do mesmo título é possível observar no artigo 22 a competência da União em legislar sobre a população indígena. Nos dias atuais é possível ver que o expresso no art. 20, XI não é totalmente posto em pratica, analisando que os territórios que outrora demarcado como reservas indígenas, estão sendo ocupadas ilegalmente por grandes proletariados, ou multinacionais que além da exploração das reservas, também utilizam da mão de obra indígena, caso que ocorre no extremo norte do país com os índios da etnia Guarani-Kaiowá. Antes da atual constituição é possível notar artigos semelhantes ao que foi citado um exemplo é encontrado no trecho de Ana Valéria Araújo, que diz respeito à constituição de 1967:

“[...] A primeira medida importante se deu no plano da formulação de novas leis, consubstanciadas em dispositivos inovadores da Constituição de 1967 e da chamada Emenda Constitucional no 1/69, que alterou profundamente a Constituição a maior inovação constituiu em incluir no texto constitucional um dispositivo que declarava as terras indígenas como parte do patrimônio da União, o que afastava, pelo menos no plano formal, o processo de esbulho que vinha sendo praticado pelos estados, além de centralizar a questão indígena na esfera federal [...] era expressamente reconhecido aos índios o direito ao usufruto exclusivo dos recursos naturais existentes em suas terras, dando-lhes a possibilidade de disporem de instrumentos jurídicos para lutar contra o desrespeito ao seu meio ambiente levado a cabo por fazendeiros, empresas mineradoras, órgãos governamentais." (ARAÚJO, 2006 p. 30).

É possível notar que a garantia a terra e exploração não é alvo apenas da atual constituição vigente, mas também foram abordadas em textos constitucionais anteriores, onde há a preocupação do legislador a respeito desse direito, que a muito não é respeitado mesmo com todos os aparatos de defesa ao índio.

\section{ÓRGÃOS DE DEFESA DAS COMUNIDADES INDÍGENAS}

A criação de órgãos de defesa das comunidades indígenas teve origem no ano de 1910, devido a ocorridos anteriores a essa data quando as disputas entre índios e proletários chegam a capital e alguns membros da sociedade começam a defender massacre dos índios que se recusarem a ajudar a civilização avançar.

“[...] O então diretor do Museu Paulista, Von Ihering, defendia o extermínio dos índios que resistissem ao avanço da civilização, promovendo grande revolta em diversos setores da sociedade civil. Em 1908, o Brasil fora publicamente acusado de massacre aos índios no XVI Congresso dos Americanistas ocorrido em Viena." (Ribeiro, 1979; Carneiro da Cunha, 1987).

No contexto da acusação em 1910 e criado o Decreto n 8.072, de 20, de junho, de 1910. Onde é criado o SPILNT (Serviço de Proteção aos Índios e Localização Nacional de Trabalhadores) que visava à proteção e integração indígena, quanto à fundação de colônias agrícolas que possuíam mão-de-obra financiada pelo Governo Federal. Com a promulgação do Decreto-Lei no. 3.454, de 6 de janeiro de 1918, o SPILNT e dividido, surgindo assim o SPI (serviço de Proteção aos Índios). O SPI circulou dentro de vários órgãos desde sua criação em 1910 até o ano de 1930, a partir da década de 1940 o SPI junto à atuação de antropólogos obstinados na valorização e Colloquium Socialis, Presidente Prudente, v. 01, n. Especial 2, Jul/Dez, 2017, p.273-277. DOI: 10.5747/cs.2017.v01.nesp2.s0148 
proteção da cultura do índio, com o Decreto no. 1.794, de 22 de novembro de 1939 surge o CNPI (Conselho Nacional de Proteção aos Índios), com o inicio da Ditadura militar em 1967 o SPI e CNPI são extintos, surgindo agora sob o nome de Fundação Nacional do Índio (FUNAI), criada pela Lei $\mathrm{n}^{\circ}$ 5.371, DE 5 de Dezembro de 1967, a FUNAl ergue-se sobre os resquícios da estrutura falida do $\mathrm{SPI}$, tendo todas as suas bases fundamentais regulamentadas pelo Congresso Nacional.

[...] a Constituição de 1891 não fazia qualquer menção aos índios ou aos seus direitos territoriais. Isto explica, por exemplo, porque o Serviço de Proteção aos Índios (SPI), que surgiu em 1910, não tinha poderes para reconhecer as terras indígenas [...] justificando as Constituições de 34, $37 \mathrm{e}$ 46 terem trazido dispositivos reconhecendo a posse dos índios sobre as terras por eles ocupadas. (ARAÚJO, 2006 p.27).

\section{ESTATUTO DO ÍNDIO}

A população indígena até 1973 ainda não possuía um estatuto que os assegurava direitos, após a criação da Lei no 6.001, de 19 de dezembro de 1973 a qual criou o Estatuto do Índio, que contém 68 artigos nos quais são tratadas as questões fundiárias, cultural, linguística, penais, patrimoniais e de saúde. Com a criação desse estatuto questões de integração começaram a ser utilizado, o intuito do estatuto é a inclusão dos indígenas aos demais brasileiros, exemplo disso está no Artigo 1ำ, Estatuto do Índio que diz: "Esta Lei regula a situação jurídica dos índios ou silvícolas e das comunidades indígenas, com o propósito de preservar a sua cultura e integrá-los, progressiva e harmoniosamente, à comunhão nacional". O estatuto funciona como um aparato aos indígenas que ainda não se incluíram na sociedade, ou seja, os considerado selvagens, aos grupos que já foram socializados além deste regramento especifico, alguns trechos do texto constitucional e aplicado como lei.

\section{OS ÍNDIOS FRENTE CONSTITUIÇÃO DE 1988}

O ordenamento constitucional vigente atualmente no país só possui o capitulo referente às comunidades indígenas da forma como é hoje, graças à luta de órgãos como UNI (União das Nações Indígenas) com o lançamento da campanha "Povos Indígenas na Constituinte". Márcio Santilli explica que: "[...] ocorre à mobilização dos índios de todo o Brasil, na tentativa de mudar a cena que se passava no congresso que na época era totalmente contraria aos índios, isso fez com que houvesse a concretização dos diretos indígenas no novo texto constitucional. (SANTILLI, Márcio. 1987/88/89/90. 1991. CEDI.)

A Constituição Federal de 1988 é a vitória dos índios que ate a década de 80 não trazia garantias aos índios como cidadãos comuns, porém, com esse texto constitucional eles o são, sendo assim assegurados os mesmos direitos dos ditos "cidadãos comuns", além dos direitos como: respeito à sua organização social, costumes, crenças e tradições, e os direitos originários sobre as terras que tradicionalmente ocupam, competindo à União demarcá-las, protegê-las e fazer respeitar todos os seus bens.

\section{SAÚDE COMO GARANTIA CONSTITUCIONAL}

A constituição de 1988 garante que a saúde é de total responsabilidade do Estado e garantida a todos, sendo assim criou-se o Sistema Único de Saúde (SUS), para atender a população de índios no país, um sistema vinculado ao SUS o SESI (Secretaria Especial de Saúde Indígena), foi criado através da Lei № 9.836/99, conhecida como Lei Arouca. Através da criação dessa lei surge uma política nacional de atenção à saúde dos povos indígenas que consiste em garantir aos povos indígenas o acesso à atenção integral à saúde, de acordo com os princípios e diretrizes do Sistema 
Único de Saúde, contemplando a diversidade social, cultural, geográfica, histórica e política de modo a favorecer a superação dos fatores que tornam essa população mais vulnerável aos agravos à saúde de maior magnitude e transcendência entre os brasileiros, reconhecendo a eficácia de sua medicina e o direito desses povos à sua cultura.

\section{O DIREITO PENAL E AS COMUNIDADES INDÍGENAS}

No ramo do Direito Penal, entende-se que quando o réu for o indígena devera sempre aplicar atenuantes, diminuindo a pena para silvícolas, em se tratando de índios isolados, não se deve aplicar as penalidade do Código Penal, porém, levar em consideração o estado do índio, no entender de Carlos Frederico Marés de Souza Filho:

"[...] num futuro próximo, quando encontrarem a alegria de viver na pacífica, doce, justa e humana sociedade dos civilizados, e então o direito penal ser-lhes-á aplicado em plenitude [devemos aplicar a lei que e vigente na realidade do individuo, não aplicar aquilo que não participa da realidade de cada grupo.]" (SOUZA FILHO, Carlos Frederico Marés de. 2004 p. 11).

O nosso direito penal ainda vê o índio como inimputável ou semi-imputável, trazendo assim a não punibilidade, ou atenuação da punição sobre os indivíduos desse grupo, dessa maneira entende Marcela Baudel de Castro no trecho de seu artigo onde cita:

"não se pode falar ainda que o Direito Penal acompanhou essa evolução de pensamento. Em que pese o surgimento de vozes na trário o indígena ainda é tratado como inimputável ou semi-imputável, excluindo-se ou atenuando-se a sua culpabilidade com motivação em um suposto desenvolvimento mental incompleto por sua não integração à sociedade [...]." (CASTRO, Marcela Baudel de. 2013)

Tipicamente o tratamento dos desiguais de maneira desigual e aplicado no caso das populações indígenas, por serem um grupo que esta a parte da sociedade o tratamentos dos mesmos deve se diferenciar na maioria dos aspectos.

O ordenamento jurídico na tentativa de não prejudicar o individuo busca não punir os indígenas da mesma forma que o ordenamento se aplica ao "homem branco".

\section{CONCLUSÃO}

Levando em consideração os expostos conclui-se que a população indígena no Brasil sempre foi tratada de maneira diferente, antes a diferença se dava pela não existência de direitos onde alguma dignidade lhes era conferida, atualmente o tratamento muda devido às garantias às quais foram asseguradas mostrando que esse grupo possui alguns privilégios, porém não muito assegurados devido à falha dos órgãos responsáveis em garanti-los, e a falta de uma fiscalização rígida. As comunidades Indígenas não estão totalmente protegidas pelo governo, ou autoridades, mesmo com todos os aparatos de proteção como FUNAI (Fundação Nacional do Índio), ainda notase uma grande negligencia sobre essa população, fazendo com que todos os direitos que são conferidos a estes sejam apenas letras em um papel frio.

\section{REFERENCIAS:}

ARAÚJO, Ana Valéria. Povos Indígenas e a Lei dos "Brancos": o direito à diferença. Brasília: 2006. P 30,27

CASTRO, Marcela Baudel de. O tratamento jurídico-penal conferido aos indígenas no ordenamento jurídico brasileiro. 2013 Disponíveis em: <https://jus.com.br/artigos/24072/o-tratamento-juridicoColloquium Socialis, Presidente Prudente, v. 01, n. Especial 2, Jul/Dez, 2017, p.273-277. DOI: 10.5747/cs.2017.v01.nesp2.s0148 
penal-conferido-aos-indigenas-no-ordenamento-juridico-brasileiro/2>. Acesso em: 12 de jun. 2016.

Ribeiro, 1979; Carneiro da Cunha, 1987.

SANTILLI, Márcio. "Os Direitos Indígenas na Constituição Brasileira". Povos Indígenas no Brasil 1987/88/89/90. 1991.

FUNAI, [2016]. Disponível em: <http://www.funai.gov.br/index. php/saude>. Acesso em 12 de jun. 2016

SOUZA FILHO, Carlos Frederico Marés de. O Renascer dos Povos Indígenas para o direito. 2004 p. 11

Projeto de Lei n. 6.001, de 19 de dezembro de 1973. Aprova o Estatuto das Sociedades Indígenas. Disponível em: <http://www.pick-upau.org.br/mundo/carta_indio/projeto_lei.htm>. Acesso: 04 de ago. 2016

LENZA, Pedro. Direito Constitucional Esquematizado. 13 ed. rev., atual. E ampla. São Paulo: Saraiva, 2009.

LEI № 11.794, DE 8 DE OUTUBRO DE 2008. Disponível em: < http://www.planalto.gov.br/ccivil_03/_ato2007-2010/2008/lei/l11794.htm >. Acesso em: 15. Jun.2016 